\title{
A Systems Biology Workflow for Drug and Vaccine Repurposing: Identifying Small-Molecule BCG Mimics to Reduce or Prevent COVID-19 Mortality
}

\author{
Rima Hajo ' (D) • Alexander Tropsha² (D)
}

Received: 11 June 2020 / Accepted: 17 September 2020 / Published online: 6 October 2020

(C) Springer Science+Business Media, LLC, part of Springer Nature 2020

\begin{abstract}
Purpose Coronavirus disease 2019 (COVID-19) is expected to continue to cause worldwide fatalities until the World population develops 'herd immunity', or until a vaccine is developed and used as a prevention. Meanwhile, there is an urgent need to identify alternative means of antiviral defense. Bacillus Calmette-Guérin (BCG) vaccine that has been recognized for its off-target beneficial effects on the immune system can be exploited to boast immunity and protect from emerging novel viruses.
\end{abstract}

Methods We developed and employed a systems biology workflow capable of identifying small-molecule antiviral drugs and vaccines that can boast immunity and affect a wide variety of viral disease pathways to protect from the fatal consequences of emerging viruses.

Results Our analysis demonstrates that BCG vaccine affects the production and maturation of naïve $\mathrm{T}$ cells resulting in enhanced, long-lasting trained innate immune responses that can provide protection against novel viruses. We have identified small-molecule BCG mimics, including antiviral drugs such as raltegravir and lopinavir as high confidence hits. Strikingly, our top hits emetine and lopinavir were independently validated by recent experimental findings that these compounds inhibit the growth of SARS-GoV-2 in vitro.

Electronic supplementary material The online version of this article (https://doi.org/l 0. I007/s I I095-020-02930-9) contains supplementary material, which is available to authorized users.

Rima Hajjo

rhajjo@gmail.com; r.hajjo@zuj.edu.jo

Department of Pharmacy - Computational Chemical Biology, Faculty of Pharmacy, Al-Zaytoonah University of Jordan, P.O. Box 130,

Amman I 1733, Jordan

2 Laboratory for Molecular Modeling, UNC Eshelman School of Pharmacy, UNC Chapel Hill, Chapel Hill, North Carolina 27599, USA
Conclusions Our results provide systems biology support for using BCG and small-molecule BCG mimics as putative vaccine and drug candidates against emergent viruses including SARS-CoV-2.

KEY WORDS BCG vaccine $\cdot$ COVID-19 - innate immunity · SARS-CoV-2 · systems biology

\begin{tabular}{|c|c|}
\hline \multicolumn{2}{|c|}{ ABBREVIATIONS } \\
\hline BCG & Bacillus Calmette-Guérin \\
\hline BIND & Biomolecular interaction network database \\
\hline BioGRID & $\begin{array}{l}\text { Biological general repository for interaction } \\
\text { datasets }\end{array}$ \\
\hline CMap & Connectivity map \\
\hline COVID- 19 & Coronavirus disease 2019 \\
\hline DIP & Database of interacting proteins \\
\hline FDA & The Food and Drug Administration \\
\hline GEO & Gene expression omnibus \\
\hline $\mathrm{GO}$ & Gene ontology \\
\hline KEGG & Kyoto encyclopedia of genes and genomes \\
\hline Mtb & Mycobacterium tuberculosis \\
\hline $\mathrm{RCTs}$ & Randomized clinical trials \\
\hline STRING & $\begin{array}{l}\text { Search tool for the retrieval of interacting } \\
\text { genes/proteins }\end{array}$ \\
\hline$/ 1$ & World Health Organization \\
\hline
\end{tabular}

\section{INTRODUCTION}

Few months after the declaration of COVID-19 pandemic by the World Health Organization (WHO), the disease-causing virus is still sweeping the globe, causing more fatalities, failing health care systems, and resulting in severe economic losses. Currently there are no approved drugs to treat COVID-19, 
and new vaccine development is expected to take at least $12-$ 18 months $(1,2)$, with growing fears of possible failure associated with changes in viral antigenic determinants (3) or shortlived immunity (4). Additionally, the highly specific virusneutralizing antibodies in recovered patients may be short lived and ineffective in preventing the disease caused by the emerging variable strains of the virus (4). With these uncertainties regarding an eminent specific SARS-CoV-2 vaccine, there is a need to search for current alternatives, such as agents that can stimulate or emulate the unique capabilities of our innate immune system.

Recent immuno-oncology success stories indicate that the best cancer-fighting strategies results from unleashing the patients' immune power (5-8). There is an increased awareness that harnessing innate immune responses, opens up new possibilities for long-term, multifaceted tumor control $(9,10)$ and infectious disease prevention (11-13). Therefore, next generation antiviral vaccines should be capable of boosting innate immune responses to tackle a wide range of novel pathogens very early after exposure, as single treatments or adjuvants to traditional vaccines targeting the adaptive immune system.

Accumulating evidence from the biomedical literature indicates that SARS-CoV-mediated pathology, a very similar pathology to SARS-CoV-2, was mainly caused by ineffective innate immune responses, associated with a severe reduction in the number of $\mathrm{T}$ cells in the blood (14). Recent evidence indicated that SARS-CoV-2 and Mycobacterium tuberculosis $(M t b)$ share unique similarities in terms of the host protein interaction partners, and both pathogens infect lung tissues (15). On the other hand, old 'polypharmacological' vaccines, such as the BCG vaccine for tuberculosis (TB), has shown promising therapeutic effects for a wide range of infectious and non-infectious diseases including bladder cancer (16-18). Studies showed that BCG's polypharmacological effects were not limited to memory $\mathrm{T}$ cell immunity, but promoted strong, beneficial, and long-lasting effects on innate immunity. The WHO also recognized these beneficial 'offtarget' effects of BCG, calling for a further investigation to repurpose this vaccine for other orphan life-threatening diseases (19). Indeed, there are multiple clinical trials testing BCG for 216 conditions other than TB including 19 studies for COVID-19 as reported on clinicaltrials.gov (20). Additionally, few recent peer-reviewed reports have pointed to an epidemiological relationship between BCG and COVID-19 without providing substantial evidence (21-24). One should expect that the results of the randomized clinical trials $(\mathrm{RCTS})$ will help establish the value of the BCG vaccine as a treatment or prophylactic against the disease.

Herein, we describe a unique drug and vaccine repurposing workflow, and list high confidence proteins and pharmacological classes of compounds, that work as BCG mimics at the system level by inducing beneficial long lasting trained immune response. We also propose that BCG mimics can be used as alternatives to BCG in protecting from COVID19 and other emergent infectious diseases.

\section{MATERIALS AND METHODS}

\section{Integrative Systems Biology Workflow}

We have developed and applied a systems biology workflow to study the BCG network pharmacology and prioritize smallmolecule BCG mimics and antivirals. This workflow is based on our original chemocentric informatics workflow described thoroughly in a previous report (25). Our current workflow (Fig. 1) incorporates three major components: (1) a module for mining and prioritizing gene signatures representative of a condition or a biological state; (2) a network-mining module to identify genetic perturbations that induce gene expression profiles that are highly enriched with the genes constituting the condition gene signature; and (3) a pathway enrichment module to understand the biological processes involved in the mechanism of action of BCG and highly correlated genetic perturbagens.

\section{BCG Consensus Gene Signature}

A consensus gene signature for BCG vaccine was derived from gene expression profiles in peripheral blood mononuclear cells (PBMCs) in response to a BCG challenge test reported by Matsumiya et al (76), GSE58636 dataset on NCBI Gene Expression Omnibus (GEO) (27). We used the data collected from whole blood samples taken from healthy human subjects enrolled in phase 1 trial (clinical trials registration: NCT01 194180). For the purposes of this study we used the gene expression profiles generated from two human subject groups included in the above trial: group 1 (BCG naive), and group 2 (BCG vaccinated; median time since vaccination, 10 years). To study network pharmacology and query the connectivity map, we developed a consensus gene signature using genes that showed significant differential gene expression in response to a BCG challenge test (stimulated) in comparison with controls (unstimulated) on days 0 and 14 in both groups 1 and 2 .

\section{Network Building}

A systematic search, for nearest neighbor (NN) genes/proteins of the upregulated and downregulated genes in BCG's gene signature, was conducted in Cytoscape (77) version 3.8.0 using the STRING (78) protein query application. All retrieved protein-protein interactions (PPIs), including both physical and functional interactions were retrieved from widely used and reliable databases such as MINT (79), HPRD (80), BIND 
(81), DIP (82), BioGRID (83), KEGG (84), Reactome (60), EcoCyc (85), NCI-Nature Pathway Interaction Database (86), and Gene Ontology (GO) (87) protein complexes. Network building tools in Cytoscape version 3.7.2 were used to generate PPI networks for BCG-CGS.

\section{Enrichment Analysis}

Enrichment analysis was conducted in Cytoscape (77) and MetaCore to identify pathways and biological processes associated with BCG-CGS and CMap genetic connections. The significance of the enrichment was determined by the hypergeometric test (88). All terms from the ontology were ranked based on their calculated $p$ values. Ontology terms with $\mathrm{p}$ values less than the $\mathrm{p}$ value threshold 0.05 are defined as statistically significant and therefore relevant to the studied list of genes. All terms from the ontology were ranked according to their calculated $\mathrm{p}$ values.

\section{The Connectivity Map (CMap)}

The CMap $(27,89)$ is a chemogenomics database that catalogs 1.3 Million profiles of transcriptional responses of human cells to chemical and genetic perturbations. Currently, there are 27,927 perturbagens (19,911 small molecules, and 7494 genetic perturbagens) producing 476,251 expression signatures in 9 human cell lines: PC3, VCAP, A375, A459, HA1E, HCC515, HT29, MCF7, HEPG2. This database of cellular signatures has been produced using the L1000 platform (27); a high-throughput gene expression assay that measures the mRNA transcript abundance of 978 "landmark" genes from human cells.

\section{Causal Reasoning}

Causal reasoning (90) analysis identifies genes and proteins of a 'topological significance' in order to make decisions whether these genes/proteins are eligible for targeting in the studied phenotype. In this study, we applied causal reasoning to identify molecular regulators that most likely directly cause the observed expression changes in transcriptional profiles in response to BCG. In this approach, changes in gene expression in both directions as well as the effect of edges in the network are taken into account. For each node (i.e., gene) in the causal reasoning network, observed changes in expression are matched with the expected changes inferred from the network structure given the hypothesis that the observed gene expression is decreased or increased due to its activity. Each node has an outgoing activation or inhibition effects on other objects in the knowledge database, and a key hub with a predicted increase in activity shows increased expression for those genes that the hub is known to activate, and it shows decreased expression for genes it is known to inhibit. Each predicted key hub has a prediction $P$ value which is produced as a result of a binomial test used to assess the probability of making a given number of supportive data out of all defined differentially expressed genes (DEGs) in the examined data. It is noteworthy that causal reasoning examines both direct neighbors of differentially expressed genes, and remote (several steps away) regulators. All causal reasoning predictions were performed in Key Pathway Advisor from Clarivate Analytics, using the Pollard method (91).

\section{R-Package Gplots}

Gplots (92) v3.0.1.2 was used for plotting enhanced heatmaps for transcriptional data (e.g., heatmap representing BCGCGS in Fig. 2). Heat maps were generated using the heatmap. 2 function included in this package.

\section{RESULTS}

\section{Drug and Vaccine Repurposing Workflow}

To study the BCG polypharmacology and potential beneficial effects of this vaccine in preventing the fatal consequences of COVID-19, we have devised and implemented a 'network biology' workflow (Fig. 1) to interrogate the hypothesis that BCG vaccination may protect from COVID-19 fatalities. This workflow is based on our drug repurposing chemocentric informatics workflow which has been validated previously for small-molecule drug repurposing (25). The current workflow is tweaked towards vaccine repurposing by employing novel bioinformatic approaches to computationally model and connect molecular networks in an effort to understand the underlying 'network' biology of vaccines, and pinpoint the regulatory genes and proteins responsible for causing the observed beneficial multitherapeutic effects. Although we are not the first group to use network biology approaches to study the transcriptional changes of vaccines, to our knowledge, this is the first study that uses these approaches both to support vaccine repurposing, specifically for COVID-19, as well as identify putative small molecule drugs that can mimic the vaccine effects.

\section{BCG Consensus Gene Signature}

Our workflow starts with the prioritization of a gene signature to study the BCG network pharmacology. First, we derived a consensus gene signature (CGS) for BCG based on GEO's dataset GSE58636 (26). Details on BCG-CGS signature are found in Table S1 (Supporting Information). Twenty-two differentially-expressed genes across all 4 experiments (2 Groups $\times 2$ time points discussed in Methods) formed 


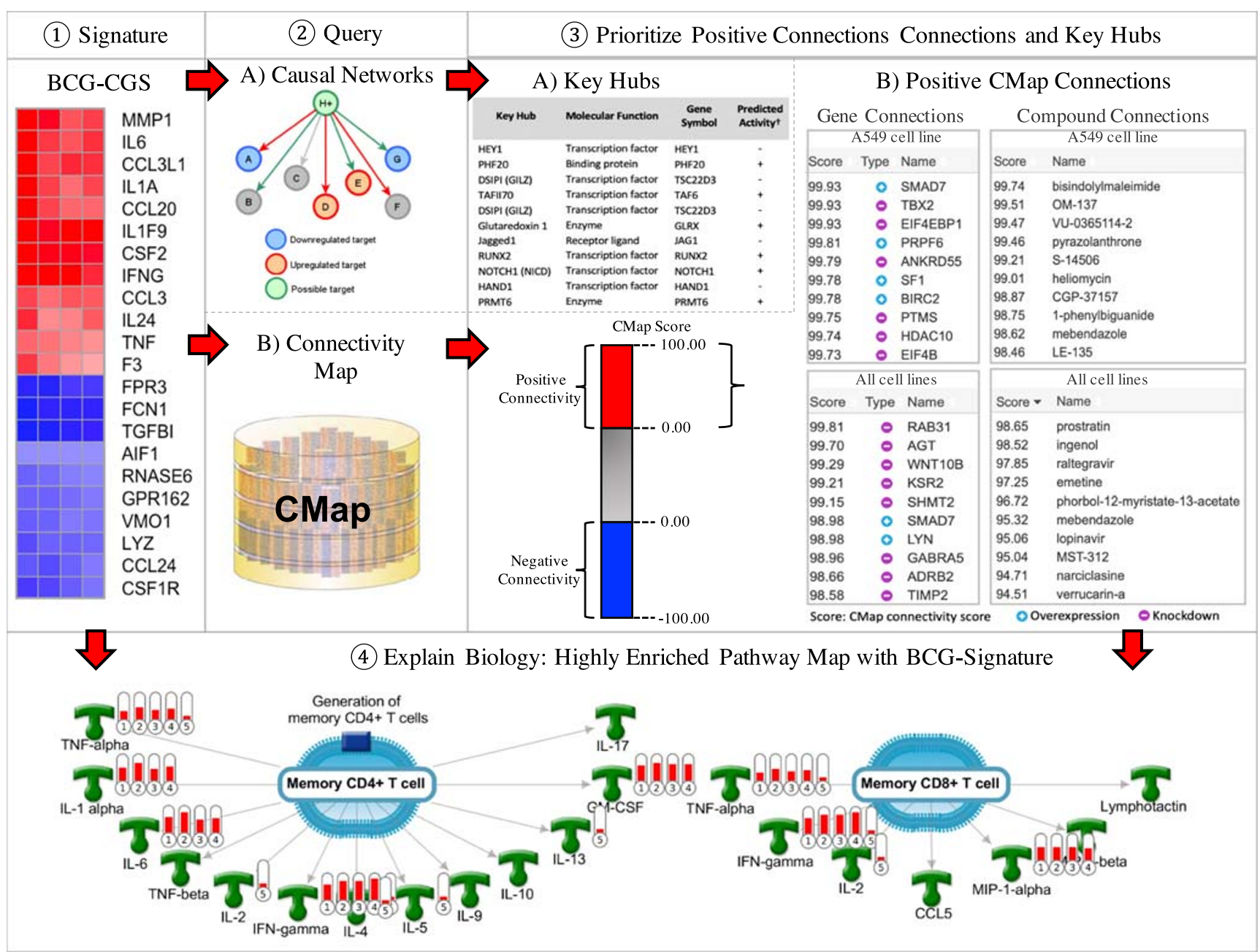

Fig. I Workflow for drug and vaccine repurposing. (1) A gene signature is identified/derived and a consensus gene signature is prioritized, all genes are nomenclated according to HUGO Gene Nomenclature Committee (HGNC). (2) The consensus gene signature is used to query the CMap to identify positive connections capable of producing gene signatures similar to BCG-CGS. (3) Prioritize genes and compounds that induce transcriptional changes similar to those induced by BCG: A) key hubs predicted by causal reasoning; B) Positive genes and compound connections from the connectivity map. (4) Prioritize top enriched pathway map explaining the biological effects of BCG (gene annotations on the pathway map are assigned by Clarivate Analytics, IFN-gamma is an alias for INFG, GM-CSF is an alias for CSF2, MIP-I-alpha is an alias for CCL3).

BCG's consensus gene signature (BCG-CGS) shown in Fig. $2 \mathrm{a}$.

\section{BCG Protein-Protein Interactions (PPIs)}

All 22 genes in BCG-CGS were used as seed nodes to build a protein-protein interaction network for signature genes (Fig. 2b). Interactions were extracted from STRING database, and high confidence interactions included physical interactions (e.g., binding), functional interactions (e.g., activation, inhibition, catalysis), or gene co-expression. Two types of networks were generated: 1) high-confidence 'core' network restricted to BCG signature genes as network nodes and high confidence $(\geq 0.70)$ interactions as network edges, and 2) mediumconfidence interaction network obtained from expanding the core network by 20 additional nodes (Fig. 3).
Enrichment analysis results performed in Cytoscape, using STRING's protein-protein interactions, indicated that BCGCGS is enriched in inflammatory cytokines and immune response modulators (Fig. 2b). Some signature genes are also involved in the negative control of important viral processes (e.g., (FGN1, TNF and CCL3), and others are involved in the response to viral infections (e.g., IFNG, RNASE6, IL6 and TNF). The complete lists of enriched pathways are included in Tables S2 and S3 (Supporting Information).

\section{Identification of Key Hubs}

We identified 291 key hubs using the causal reasoning method, which seeks to identify molecular regulators that can directly cause the observed transcriptional changes in response to BCG vaccination. Key regulators can be transcriptional factors and proteins with potentially altered activity that 

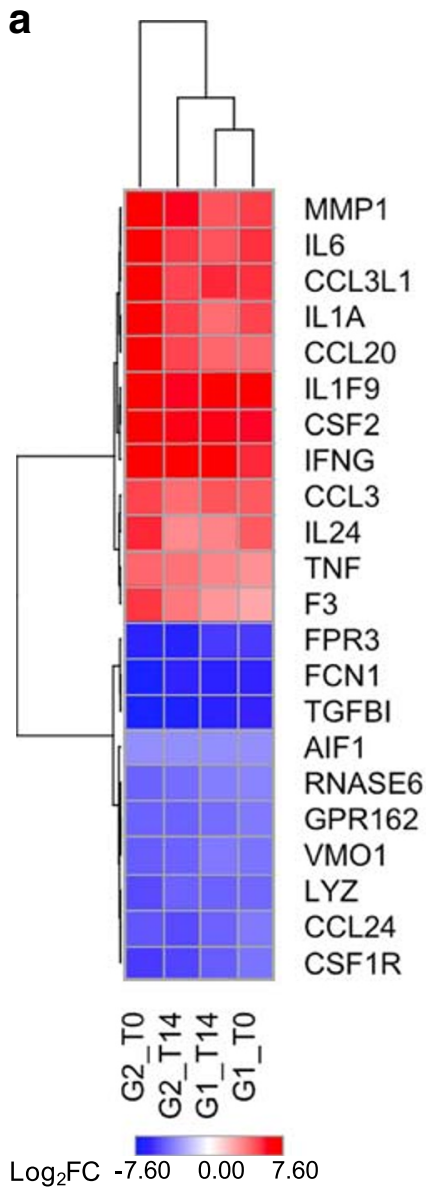

b

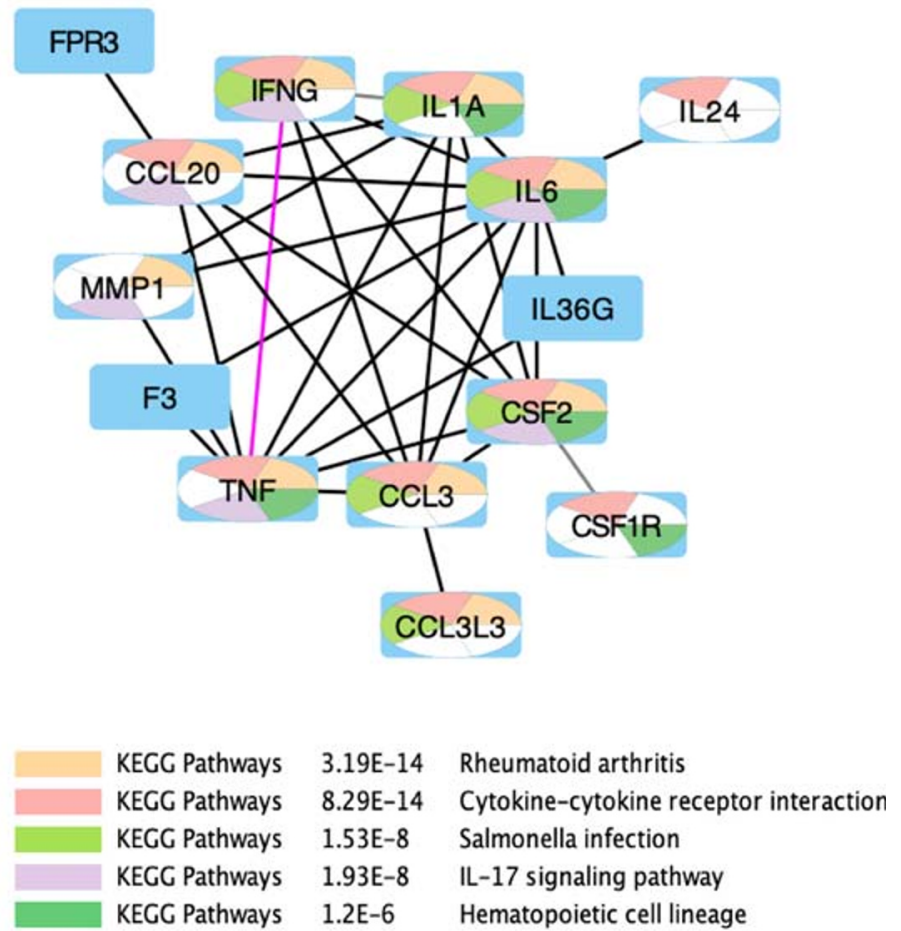

Fig. 2 BCG's consensus gene signature (BCG-CGS) and highly enriched pathways. (a) A heat map of the $\log _{2} \mathrm{FC}$ of the gene expression for differentially expressed genes representing BCG's consensus gene signature. Upregulated genes have positive $\log _{2} \mathrm{FC}$ denoted in red color, and down regulated genes have negative values for $\log _{2}$ FC denoted in blue color. (b) Core network for BCG-CGS showing highly connected genes in BCG-CGS, deleting all singleton genes. Nodes are color-coded using a split pie chart coloring scheme indicating pathway/gene set contribution to each node from the top 5 most enriched pathways/ gene lists. All details about pathway/gene set ID are found in Table S2 (Supporting Information).

explains the transcriptional changes. Top five statistically significant inhibited key hubs included HEY1, DSIPI (GILZ), Jagged1, HAND1 and miR-129-1-3p, whereas top five statistically significant activated key hubs were PHF20, TAFII70, Glutaredoxin, RUNX2 and NOTCH1 (NICD). Top 30 causal key hubs are shown in Table I and all identified 291 key hubs are included in Table S4 (Supporting Information).

\section{Identifying BCG 'Mimics'}

In order to identify experimentally validated upstream regulators that cause transcriptional changes similar to those induced by BCG, we queried the Connectivity Map (CMap) (27) database of the Broad Institute with BCGCGS and identified proteins and small-molecule drugs that have strong connectivity scores with BCG (Fig. 1). The GMap approach enabled us to compare BCG-CGS with 'experimentally' predefined signatures of therapeutic compounds and genetic perturbations (i.e., over expression or knockdown) included in the CMap and ranked according to a connectivity scores (ranging from +100 to -100 ), representing relative similarity to BCG-CGS. The connectivity score itself is derived using a nonparametric, rankbased, pattern-matching strategy based on the Kolmogorov-Smirnov statistics (28). All instances in the database are then ranked according to their connectivity scores with BCG-CGS; those at the top (+) are most strongly correlated to the query signature and looked at as BCG mimics, and those at the bottom $(-)$ are most strongly anticorrelated and can reverse BCG's gene signature.

Our analysis identified three highly enriched classes of genetic knockdown (KD) perturbagens and one pharmacological class of drugs that have positive connectivity scores in alveolar A549 cells (i.e., caused similar transcriptional changes to those induced by BCG in alveolar A549 cells). These hits can be considered as BCG mimics capable of inducing transcriptional changes similar to those caused by the BCG vaccine. Therefore, we suggest that BCG mimics can be used as alternatives to $\mathrm{BCG}$ vaccination to promote long-lasting 


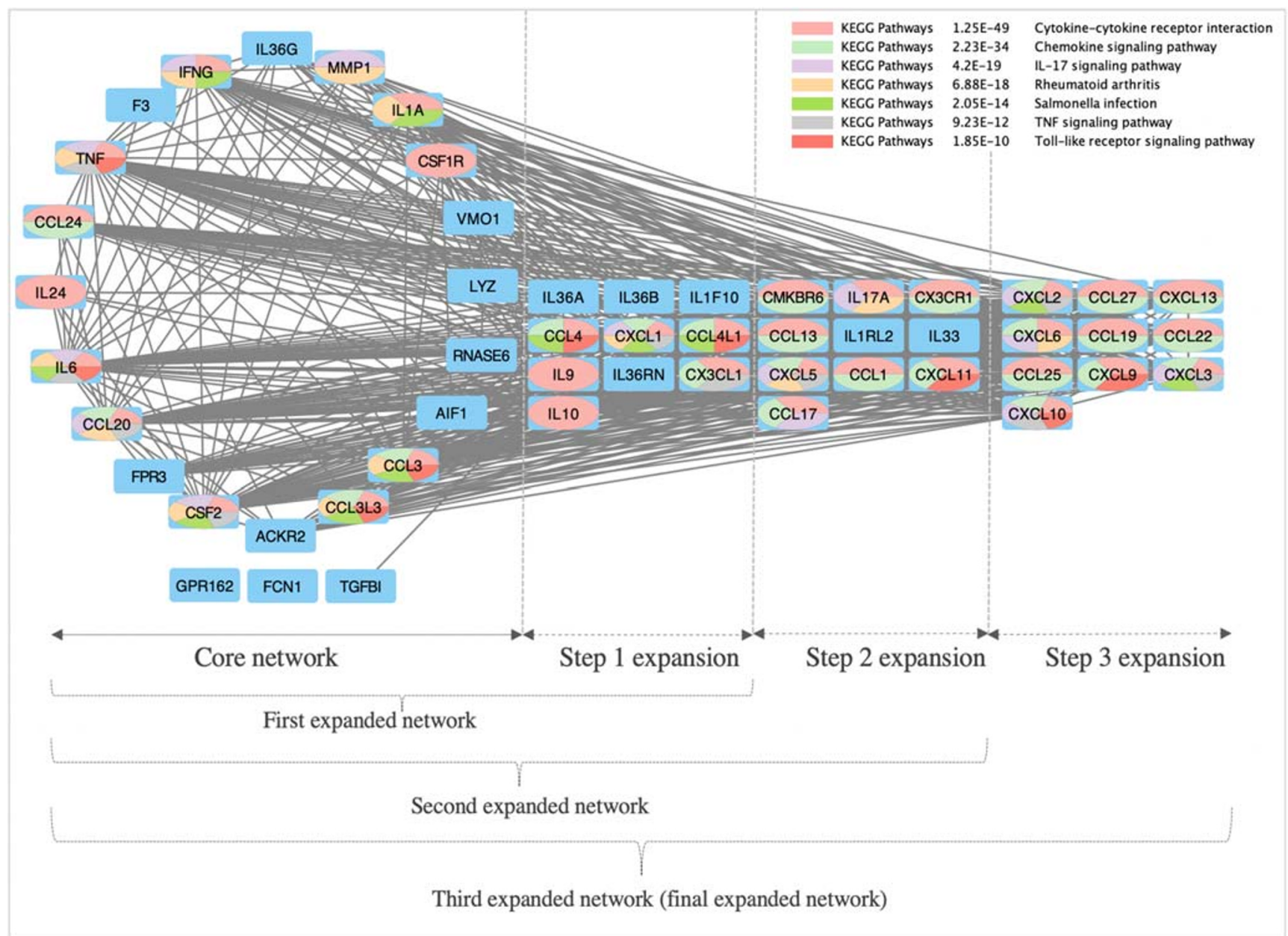

Fig. 3 High-confidence expanded network for BCG-CGS. Nodes are color-coded using a split pie chart coloring scheme indicating pathway/gene set contribution to each node from the top 5 most enriched pathways/gene lists. Core network is composed of genes in the BCG-CGS that are not singletons. Step I expansion, added 10 additional nodes (i.e., genes) to the core network. Step 2 expansion, added another 10 nodes for the first expansion. Step 3 expansion, added another 10 nodes to the second expansion. Expansions were performed to see which pathways remained most statistically significant, and therefore are considered high confidence pathways.

beneficial effects on immune cells. The three enriched protein classes are: protein phosphatases (with best positive connection for PPP4C KD), histone deacetylases (with best positive connection for HDAC10 KD followed by HDAC11 KD), and mediator complex proteins (with best positive connection for MED6 KD followed by MED7 KD). Additionally, protein kinase $\mathrm{C}(\mathrm{PKC})$ activators were enriched as a drug class; and top three PKC activators with highest CMap connectivity scores to BCG-CGS were prostratin, phorbol-12-myristate13-acetate, and ingenol. It is evident that all of the above four classes of proteins share one common feature: they participate in the transcriptional and metabolic regulation of immune cells in response to environmental cues including responses to pathogens (29-32). All top-scoring PKC activators from the CMap, are also known to have antiviral effects or affect T cell activation (33-37).

Remarkably, analyzing top ten CMap positive connections with BCG-CGS obtained from nine cell lines indicated that two compounds are approved antiviral drugs: raltegravir (top 3rd positive connection, an HIV integrase inhibitor) and lopinavir (top 6th positive connection, an HIV protease inhibitor). More interestingly, emetine (top 4th positive connection) and lopinavir were recently validated to inhibit SARS-CoV-2 replication in vitro (38). We also found evidence in the biomedical literature indicating that MST-312 (39), narciclasine (40) and verrucarin-a (41) possess antiviral activities. All CMap hits are provided in Tables S5 and S8 (Supporting Information).

Initial reports from clinical studies evaluating the use of lopinavir in COVID-19 patients showed that the unbound lopinavir concentrations in the lungs were calculated to be subtherapeutic against SARS-CoV-2 $(42,43)$. Another study found that the unbound drug concentrations of lopinavir are far from reaching the EC50 of SARS-CoV-2 $(16.4 \mu \mathrm{g} / \mathrm{mL})$, although they clearly suffice to inhibit HIV-1 (44). The authors mentioned 
Table I Top Thirty Key Hubs Predicted by Causal Reasoning

\begin{tabular}{|c|c|c|c|c|c|c|}
\hline Key Hub & Molecular function & Gene symbol & Predicted activity† & Correct/Total network predictions $\ddagger$ & $\begin{array}{l}\text { Activity prediction } \\
P \text { value* }\end{array}$ & $\begin{array}{l}\text { Calculation } \\
\text { distance§ }\end{array}$ \\
\hline HEYI & Transcription factor & HEYI & - & $15 / 15$ & 3.05E-05 & 3 \\
\hline PHF20 & Binding protein & PHF20 & + & $15 / 15$ & $3.05 \mathrm{E}-05$ & 3 \\
\hline DSIPI (GILZ) & Transcription factor & TSC22D3 & - & $14 / 14$ & 6. $10 \mathrm{E}-05$ & 3 \\
\hline TAFII70 & Transcription factor & TAF6 & + & $14 / 14$ & 6. $10 \mathrm{E}-05$ & 3 \\
\hline DSIPI (GILZ) & Transcription factor & TSC22D3 & - & $13 / 13$ & $1.22 \mathrm{E}-04$ & 2 \\
\hline Glutaredoxin I & Enzyme & GLRX & + & $13 / 13$ & $1.22 \mathrm{E}-04$ & 3 \\
\hline Jagged I & Receptor ligand & $|A G|$ & - & $13 / 13$ & 1.22E-04 & 3 \\
\hline RUNX2 & Transcription factor & RUNX2 & + & $13 / 13$ & $1.22 \mathrm{E}-04$ & 2 \\
\hline NOTCHI (NICD) & Transcription factor & NOTCHI & + & $16 / 17$ & 1.37E-04 & 3 \\
\hline HANDI & Transcription factor & HANDI & - & $12 / 12$ & 2.44E-04 & 3 \\
\hline PRMT6 & Enzyme & PRMT6 & + & $12 / 12$ & 2.44E-04 & 2 \\
\hline miR-129-I-3p & RNA & MIRI29-I & - & $12 / 12$ & 2.44E-04 & 3 \\
\hline SOXI0 & Transcription factor & sox 10 & + & $12 / 12$ & 2.44E-04 & 3 \\
\hline HAND2 & Transcription factor & HAND2 & - & $12 / 12$ & 2.44E-04 & 3 \\
\hline MSKI & Protein kinase & RPS6KA5 & + & $12 / 12$ & 2.44E-04 & 2 \\
\hline USP28 & Protease & USP28 & + & $15 / 16$ & $2.59 \mathrm{E}-04$ & 3 \\
\hline c-Fos & Transcription factor & FOS & + & $15 / 16$ & $2.59 \mathrm{E}-04$ & 3 \\
\hline UBF & Transcription factor & UBTF & + & ||$/||$ & $4.88 \mathrm{E}-04$ & 3 \\
\hline miR-520e-3p & RNA & MIR520E & - & ||$/||$ & $4.88 \mathrm{E}-04$ & 2 \\
\hline TMEMII9 & Protein & TMEMII9 & + & ||$/||$ & $4.88 \mathrm{E}-04$ & 3 \\
\hline LRPI 6 & Binding protein & MACRODI & + & $|1 /| \mid$ & $4.88 \mathrm{E}-04$ & 2 \\
\hline LRPI 6 & Binding protein & MACRODI & + & $14 / 15$ & $4.88 \mathrm{E}-04$ & 3 \\
\hline CaMK II gamma & Protein kinase & CAMK2G & + & ||$/||$ & $4.88 \mathrm{E}-04$ & 2 \\
\hline CaMK II gamma & Protein kinase & CAMK2G & + & $14 / 15$ & $4.88 \mathrm{E}-04$ & 3 \\
\hline miR-4500 & RNA & MIR4500 & - & $14 / 15$ & $4.88 \mathrm{E}-04$ & 3 \\
\hline NOTCHI (NICD) & Transcription factor & NOTCHI & + & $14 / 15$ & $4.88 \mathrm{E}-04$ & 2 \\
\hline miR-45I6 & RNA & MIR45I 6 & - & ||$/||$ & $4.88 \mathrm{E}-04$ & 3 \\
\hline NDPK B & Protein kinase & NME2 & - & $|1 /| \mid$ & $4.88 \mathrm{E}-04$ & 3 \\
\hline KLFII (TIEG2) & Transcription factor & KLFII & - & ||$/||$ & $4.88 \mathrm{E}-04$ & 2 \\
\hline miR-320d & RNA & MIR320DI & - & $14 / 15$ & 4.88E-04 & 3 \\
\hline
\end{tabular}

† Predicted activity of the key hub by causal reasoning is denoted by - if the hub is inhibited, and denoted by + if the hub is activated

¥ Correct/total network predictions: correct for the genes in the dataset predicted correctly; total for the total number of genes in the causal reasoning network $\S$ Calculation distance: Using causal reasoning one-step key hubs are defined as statistically significant transcriptional factors that are associated with experimental differential expressed genes regulation. Two-step and three-step key hubs are distant key hubs that regulate one-step transcriptional factors

* $P$-value calcualted for the polynomial test

that approximately 60- to 120 -fold higher concentrations than those found in COVID-19 patients treated with lopinavir-ritonavir, are required to reach the assumed EC50 at trough levels, making effective treatment of COVID-19 with lopinavir and ritonavir at the currently used doses unlikely (44).

In order to prioritize high confidence $\mathrm{BCG}$ genetic mimics, we integrated hypotheses derived independently from the CMap with those predicted by causal reasoning, and accepted common hits only (i.e., CMap positive connections with BCGCGS that are also predicted as beneficial drug targets by causal reasoning). This analysis resulted in 30 high confidence common hits reported in Table S9 (Supporting Information).

\section{Can We Validate Functional Connections Between BCG and SARS-CoV-2?}

We tested whether BCG-CGS, CMap positive connections, or predicted key hubs will have any impact on COVID-19 by identifying overlaps with SARS-CoV-2 interactome, i.e., human proteins that were experimentally validated to interact with SARS-CoV-2 and extracted from two recent reports $(45,46)$. This analysis (Fig. 4a) validated 3 protein hits to have physical links to SARS-CoV-2. The three proteins are transcribed by BRD4, PRKACA and SIRT5; they all were positive connections from the CMap, predicted as statistically 
significant key hubs, and were also validated as SARS-CoV-2 interacting proteins (15).

Additionally, 14 high-confidence CMap positive connections, were validated to make physical interactions with SARS-CoV-2 proteins. These proteins are: PSEN2, PABPC1, HMOX1, CIT, PLAT, IGF2R, RIPK1, NDUFS3, NDUFA5, GGH, NEU1, SCARB1, CSNK2B, F2RL1. And two positive connections, MARK2 and MARK3, were reported to have interactions with corona viruses (45). Predicted causal key hubs, SIGMAR1 and GNB1, were also validated to have physical links to SARSCoV-2 (15), and a third key hub PPIA was known as a human protein interacting with proteins from corona viruses (45).

Additionally, we mined the biomedical literature to identify evidence for linking BCG small molecule mimics with SARS$\mathrm{CoV}-2$, corona viruses or viral infections in general. We found that two out of ten top positive compound connections (emetine and lopinavir), were recently validated to inhibit SARSCoV-2 replication in vitro (38). Other compounds we found to inhibit the growth of corona viruses, or had general antiviral activities (Table II).

\section{DISCUSSION}

Previous peer-reviewed reports indicated that BCG's nonspecific effects on the immune system, can reduce all-cause child mortality (47), protect individuals from numerous viral infections (48-52), and it can even enhance the efficiency of some viral vaccines (53-55). Recently, several peer-reviewed studies have pointed to a striking correlation between universal BCG vaccination policies and reduced COVID-19 mortality (23). However, most epidemiological studies identified this correlation without acknowledging other important study confounders like social, economic, and demographic differences between countries. Lately, Escobar et al. mitigated multiple confounding factors for the first time and still observed several significant associations between $\mathrm{BCG}$ vaccination and reduced COVID-19 deaths (21). The authors of this study highlighted the need for mechanistic studies behind the effect of BCG vaccination on COVID-19, and for clinical evaluation of the effectiveness of BCG vaccination to protect from severe COVID-19. Earlier studies suggested that the documented beneficial off-target effects of BCG in protecting from nonTB infections, including perhaps COVID-19, involve a potentiation of innate immune responses through epigenetic mechanisms (56-58).

To our knowledge, we report here on the first study providing a mechanistic insight to explain the relationships between BCG and COVID-19 at the molecular and systems biology levels as well as extend this insight toward proposing several BCG mimetics among known drugs as candidates for repurposing against the disease. Our results indicate that
BCG-CGS, key regulatory hubs and BCG-mimics identified from the CMap enrich common biological pathways important for key viral processes such as RNA synthesis and processing, virus-host interactions, positive regulation of viral genome replication, and they are also important for the immune response mounted against the virus. Supporting evidence from the biomedical literature confirms that BCG has many beneficial 'off-target' effects that can protect humans from emerging novel pathogens by boasting their innate immune responses (59). Our studies suggest that BCG promotes a wide-range of transcriptional and metabolic changes, including beneficial gene commensalism, that have been shown to reduce mortality and morbidity from non-TB infectious diseases $(51,52)$. We show that BCG can produce these protective 'off target' effects mainly by increasing the production of thymus-generated short-lived undifferentiated CD4+ cells known as naive $\mathrm{T}$ cells $\left(\mathrm{Th}_{0}\right)$, and triggering their differentiation into the long-lived mature naive T cells (MNTs), such as CD4+ and CD8+ T cells (60). Interestingly, a very recent study published in Science (61) showed that many unexposed patients (20-50\%) carry selective and cross-reactive SARSCoV-2 T cell epitopes protecting patients against severe infection. Another recent study in Cell (62) reported similar observation of strong SARS-CoV-2 selective memory T cell immunity (reminiscent of the functional patterns observed after successful vaccine immunizations) in patients with asymptomatic or mild infections. Although these studies make no connection to any previous BCG vaccination as a source of selective epitopes, we observe that these observations are consistent with our mechanistic hypothesis concerning the protective effect of BCG against COVID-19. These conclusions are supported by the enrichment results produced using the 'Compare Experiment' algorithm in MetaCore from Clarivate Analytics, which looks for significant coordinated gene expression effects across all experiments to test whether the pathway is being up- or down-regulated in a manner that is unlikely to be accounted for by random chance. The top enriched pathway map, with upregulated genes in response to BCG, is 'Immune response T cell subsets: secreted signals' (Fig. 4b). A recent study showing that SARS-CoV-2 reshapes central cellular pathways, such as translation, splicing, carbon metabolism and nucleic acid metabolism (53), provides further support for this observation.

Naturally, bioinformatics techniques relying on gene expression, pathway over-representation and network biology have some limitations and biases: 1) results are impacted by the user-selected cut-off thresholds used to determine significant genes, which could make the results userdependent (63); 2) all components in the pathway are given equal weights without paying attention to the nature of the interactions between the different components (64); 3) there are underlying assumptions that pathways are independent of each other, contrary to the fact that pathways 
Fig. 4 (a) A venn diagram showing overlaps between BCG genetic mimics and key hubs with SARSCoV-2 and Corona viruses interactomes. (b) Top "pathway map" with the highest level of enrichment by genes in BCG-CGS. This map is generated using MetaCore from Clarivate Analytics. Red thermometers indicate genes overexpressed in response to BCG treatment, and the hight of the red bars is representative of the differential gene expression level (i.e., $\log _{2}$ values of the fold change). The numbers under the thermometers $I-5$ refer to the experiment number: I) gene expression on day 0 in response to $B C G$ vaccination to a $B C G$-naïve population on day 1 ; 2) gene expression on day 0 in response to BCG re-vaccination to a previously vaccinated population; 3) gene expression on day 14 in response to $B C G$ vaccination to a $B C G$-naïve population; 4) gene expression on day 14 in response to BCG revaccination to a previously vaccinated population, and 5) positive connections from the connectivity map, and the red bar in the thermometer number 5 represents presence of the gene only.

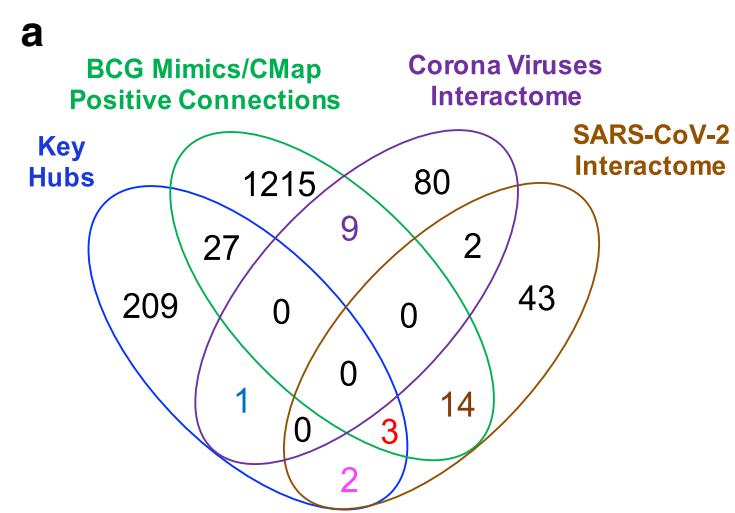

Overlaps with SARS-CoV-2 and Corona viruses interactomes:

$\begin{array}{llll}\text { PRKACA } & \text { EIF4B } & \text { PABPC1 } & \text { NEU1 } \\ \text { SIRT5 } & \text { RYBP } & \text { HMOX1 } & \text { SCARB1 } \\ \text { BRD4 } & \text { PPIG } & \text { CIT } & \text { CSNK2B } \\ \text { SIGMAR1 } & \text { ATF5 } & \text { PLAT } & \text { F2RL1 } \\ \text { GNB1 } & \text { CAMLG } & \text { IGF2R } & \text { PSEN2 } \\ \text { PPIA } & \text { BCL2L1 } & \text { RIPK1 } & \\ & \text { TBCB } & \text { NDUFS3 } & \\ & \text { DDAH2 } & \text { NDUFA5 } & \\ & \text { CAV1 } & \text { GGH } & \end{array}$

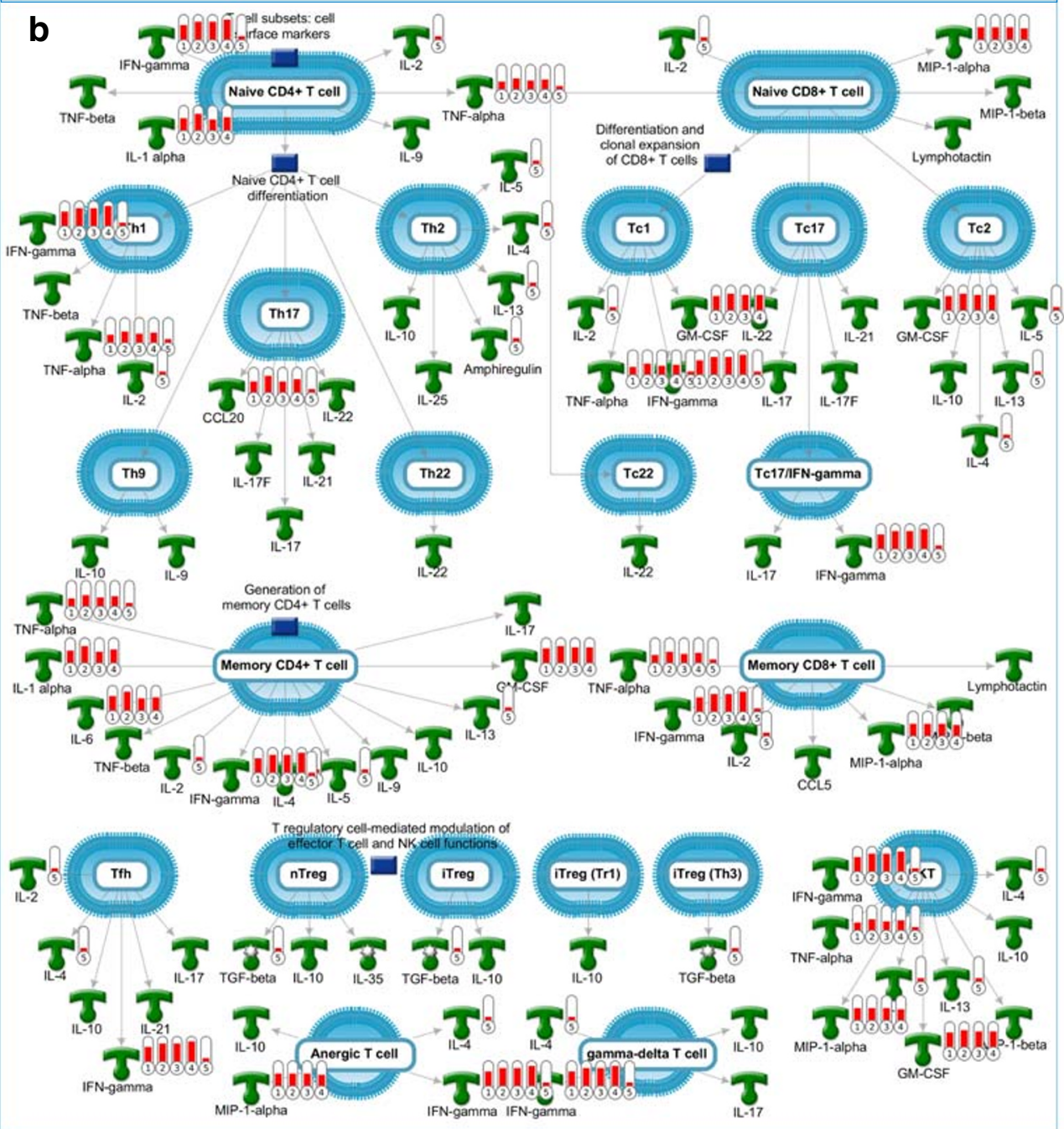

cross-talk and overlap (65); 4) assuming independence between genes may result in false positive predictions of highly enriched genes or gene sets (66); 5) these methods are incapable of modeling an organism's biology as a dynamic system, and cannot predict changes in the system due genetic mutations or environmental changes (67); 6) most pathway knowledge databases are built by curating experiments performed in different cell types at different time points under different conditions, so they are missing condition- and cell-specific information (64).

In order to mitigate some of the aforementioned limitations, we used a consensus gene signature since it is more stable than other gene expression signatures, we paired overrepresentation pathway analysis with causal reasoning to 
Table II Small-Molecule BCG Mimics with Potential Antiviral Effects

\begin{tabular}{|c|c|c|c|}
\hline Compound & Scoret & Description & Validation $\neq$ \\
\hline prostratin & 98.65 & PKC activator & Antiviral (34) \\
\hline ingenol & 98.52 & PKC activator & Antiviral (33) \\
\hline raltegravir & 97.85 & HIV integrase inhibitor & Antiviral (93) \\
\hline emetine & 97.25 & Protein synthesis inhibitor & SARS-CoV-2 (38) \\
\hline phorbol-12-myristate-13-acetate & 96.72 & PKC activator & Antiviral $(36,37)$ \\
\hline mebendazole & 95.32 & Tubulin inhibitor & Antiviral (94) \\
\hline lopinavir & 95.06 & HIV protease inhibitor & SARS-CoV-2 $(38,39)$ \\
\hline MST-312 & 95.04 & Telomerase inhibitor & Antiviral $(36,37,39)$ \\
\hline narciclasine & 94.71 & Cofilin signaling pathway activator & Antiviral (40) \\
\hline verrucarin-a & 94.51 & Protein synthesis inhibitor & Antiviral (95) \\
\hline anisomycin & 94.40 & DNA synthesis inhibitor & Corona viruses (96) \\
\hline azacitidine & 94.29 & DNA methyltransferase inhibitor & Antiviral (97) \\
\hline cytochalasin-b & 93.90 & Microtubule inhibitor & Antiviral (98) \\
\hline cephaeline & 93.88 & Protein synthesis inhibitor & Antiviral (99) \\
\hline homoharringtonine & 93.42 & Protein synthesis inhibitor & Antiviral (100) \\
\hline ruxolitinib & 92.81 & JAK inhibitor & COVID-19 CT§ \\
\hline$H U-2 I I$ & 92.64 & Glutamate receptor antagonist & Unknown \\
\hline vinblastine & 92.36 & Microtubule inhibitor & Unknown \\
\hline RO-28-1675 & 92.12 & Glucokinase activator & Unknown \\
\hline vincristine & 91.61 & Tubulin inhibitor & Unknown \\
\hline
\end{tabular}

†Score refer to the CMap score. It represents the level of similarity between transcriptional effects induced by BCG and each of the compounds

¥ Validation refers to the presence of any supporting evidence from the biomedical literature that the predicted BCG mimics have any antiviral activities. Antiviral means there is evidence that the compound is used as or has antiviral activity; SARS-CoV-2 means that the compound should antiviral activity against SARS-CoV-2; Corona viruses means that the compound showed antiviral activity against corona viruses other than SARS-CoV-2

$\S$ COVID- 19 CT: there is evidence that the compound is being tested in clinical trials for COVID-19. There are I 2 Studies found for Ruxolitinib in COVID- I9 on clinicaltrials.gov.

predict protein activities based on the nature of interactions between upregulated or downregulated genes, and we also integrated results from several bioinformatics methods such as causal reasoning and CMap predictions to prioritize common hypotheses.

A recent publication (68) in Lancet has questioned whether BCG's effects can last for a long time. Our top enriched pathway map (Fig. 4b) indicates that BCG's effects can be longlasting if the effects were exerted on thymus-generated $\mathrm{Th}_{0}$ cells, which can occur to a greater extent very early in life before reaching thymic involution by puberty (69). This pathway map indicates that BCG is capable of affecting both the numbers and the types of produced innate immune cells, as well as their maturation to long-lived memory $\mathrm{T}$ cells (i.e., what is known as trained immunity). This is very significant in the context of BCG's protective effects from SARS-CoV-2 and other emergent novel viruses where the individual's ability to eradicate such viruses is dictated by the number and diversity of naive $\mathrm{T}$ cell reservoir $(70,71)$. Our analysis suggest that BCG may protect individuals from novel pathogens by priming their trained immunity to fight such pathogens, including SARS-CoV-2.
Supporting evidence for this hypothesis is found in the literature (72) indicating that the protective effects of the BCG against $\mathrm{TB}$, can last from 15 to 60 years after vaccination (72,73), with longer lasting effects when the vaccine is administered during the first year of life $(74,60)$. A recent study indicated that "school-aged BCG vaccination offered moderate protection against tuberculosis for at least 20 years, which is much longer than previously thought" $(60,72)$. Another 60year follow-up study, showed that BCG vaccine efficacy persisted for 50 to 60 years after a single dose of BCG (60). Of special interest is a recent study that showed that mucosal vaccination resulted in an increased frequency of antigenspecific lung tissue-resident CD4+ T cells that provide longterm immunity (75). These studies serve as additional evidence from the literature supporting our claim that a single dose of an 'effective' BCG vaccination to infants can have a very long duration of protection against pathogens including SARS-CoV-2.

Our findings provided systems biology support for using BCG to protect from the severe consequences of COVID19. BCG is currently on WHO's List of Essential Medicines; it is considered one of the safest and most effective medicines 
needed in a health system. There is also evidence indicating that BCG can improve the response to vaccines directed against viral infections (48,53-55), which may prove useful when SARS-CoV-2-specific vaccines become available. Therefore, we suggest that administering the BCG vaccine to all newborns may protect them from the infection by SARS-CoV-2 and other emerging pathogens.

Since this is an approved vaccine for TB, it can directly enter Phase III testing for the protection from COVID-19 caused fatalities. However, we caution that running these experiments during an active COVID-19 outbreak, might expose participants to aggravated immune responses if they contract COVID-19 during the study. We also advise that clinical study design takes into account several factors that are known to affect the performance of BCG vaccine, such as: the age of the participants, geographies, ethnicities, route of administration and the mycobacterium strain used in the vaccine. It is equally important to run experimental validation studies, to evaluate the effects of BCG mimics, in preventing COVID-19 or for treating urological cancers.

\section{CONCLUSION}

Our results provide systems biology support for using BCG and small-molecule BCG mimics as putative vaccine and drug candidates against emergent viruses including SARS-CoV-2. Of course, any practical actions to repurpose this vaccine as a means of protection against SARS-CoV-2, or other novel viruses, should be preceded by the successful in vitro and animal experimentation. We also caution that previous studies showed that the protective effects of BCG were found to be weaker when the vaccine was given after the first year of life and particularly after puberty (68).

\section{ACKNOWLEDGMENTS AND DISCLOSURES. RH} acknowledges support from the Deanship of Scientific Research at Al-Zaytoonah University of Jordan grant 20202019/17/03. AT acknowledges partial support from NIH grant OT2TR003441. We thank Clarivate Analytics for providing access to MetaCore, a specialized pathway and functional genomics analysis product. Reference to commercial products or services does not constitute their endorsement.

\section{AUTHOR CONTRIBUTIONS}

R. Hajjo generated the idea, designed the workflow, generated content, performed data analysis and wrote the manuscript. A. Tropsha was engaged in the critical discussion of the study design, recommended some studies, and edited the manuscript.
Data Availability BCG dataset, GSE58636 is available on the Gene Expression Omnibus GEO: https://www.ncbi.nlm.nih.gov/geo/query/acc. cgi?acc $=$ GSE58636

\section{COMPLIANCE WITH ETHICAL STANDARDS}

Conflict of Interest The authors declare no competing interests.

\section{REFERENCES}

1. Lurie N, Saville M, Hatchett R, Halton J. Developing covid-19 vaccines at pandemic speed. New England Journal of Medicine. Massachussetts Medical Society; 2020. p. 1969-1973.

2. Hanney SR, Wooding S, Sussex J, Grant J. From COVID-19 research to vaccine application: Why might it take 17 months not 17 years and what are the wider lessons? Health Research Policy and Systems [Internet]. BioMed Central Ltd.; 2020 [cited 2020 Aug 14];18. Available from: https://pubmed.ncbi.nlm.nih. gov/32513202/

3. Tizard IR. Vaccination against coronaviruses in domestic animals [Internet]. Vaccine. Elsevier Ltd; 2020 [cited 2020 Aug 23]. p. 5123-30. Available from: https://pubmed.ncbi.nlm.nih.gov/ 32563608/

4. Bloch EM, Shoham S, Casadevall A, Sachais BS, Shaz B, Winters JL, et al. Deployment of convalescent plasma for the prevention and treatment of COVID-19 [Internet]. Journal of Clinical Investigation. American Society for Clinical Investigation; 2020 [cited 2020 Aug 23]. p. 2757-65. Available from: https:// pubmed.ncbi.nlm.nih.gov/32254064/

5. Zhang Y, Zhang Z. The history and advances in cancer immunotherapy: understanding the characteristics of tumor-infiltrating immune cells and their therapeutic implications [internet]. Cellular and Molecular Immunology. Springer Nature; 2020 [cited 2020 Aug 23]. p. 807-21. Available from. https://doi.org/10. 1038/s41423-020-0488-6.

6. Sharma P, Wagner K, Wolchok JD, Allison JP. Novel cancer immunotherapy agents with survival benefit: Recent successes and next steps [Internet]. Nature Reviews Cancer. NIH Public Access; 2011 [cited 2020 Aug 23]. p. 805-12. Available from: https://www.pmc/articles/PMC3426440/?report=abstract.

7. Kruger S, Ilmer M, Kobold S, Cadilha BL, Endres S, Ormanns S, et al. Advances in cancer immunotherapy 2019 - Latest trends [Internet]. Journal of Experimental and Clinical Cancer Research. BioMed Central Ltd.; 2019 [cited 2020 Aug 23]. Available from: https://www.pmc/articles/PMC6585101/? report $=$ abstract.

8. Harris SJ, Brown J, Lopez J, Yap TA. Immuno-oncology combinations: raising the tail of the survival curve [Internet]. Cancer Biology and Medicine. Cancer Biology and Medicine; 2016 [cited 2020 Aug 23]. p. 171-93. Available from: https://www.pmc/ articles $/$ PMC4944548/?report=abstract.

9. Demaria O, Cornen S, Daëron M, Morel Y, Medzhitov R, Vivier E. Harnessing innate immunity in cancer therapy. Nature Nat Publ Group; 2019. p. 45-56.

10. Dar TB, Henson RM, Shiao SL. Targeting innate immunity to enhance the efficacy of radiation therapy. Frontiers in Immunology. Frontiers Media S.A.; 2019. p. 3077.

11. Pattabhi S, Wilkins CR, Dong R, Knoll ML, Posakony J, Kaiser S, et al. Targeting innate immunity for antiviral therapy through small molecule agonists of the RLR pathway. Journal of Virology American Society for Microbiology. 2016;90:2372-87.

12. Seth RB, Sun L, Chen ZJ. Antiviral innate immunity pathways. Cell Research. Nat Publ Group; 2006. p. 141-147. 
13. White MR, Doss M, Boland P, Tecle T, Hartshorn KL. Innate immunity to influenza virus: Implications for future therapy. Expert Review of Glinical Immunology. NIH Public Access; 2008. p. 497-514.

14. Channappanavar R, Zhao J, Perlman S. T cell-mediated immune response to respiratory coronaviruses [internet]. Immunologic research. Humana press Inc.; 2014 [cited 2020 Apr 11]. p. 118-28. Available from. https://www.ncbi.nlm.nih.gov/pubmed/ 24845462.

15. Gordon DE, Jang GM, Bouhaddou M, Xu J, Obernier K, White $\mathrm{KM}$, et al. A SARS-CoV-2 protein interaction map reveals targets for drug repurposing. Nature [Internet]. Nature Publishing Group; 2020 [cited 2020 Apr 30];1-13. Available from: http:// www.nature.com/articles/s41586-020-2286-9

16. Covián C, Fernández-Fierro A, Retamal-Díaz A, Díaz FE, Vasquez AE. Lay MK, et al. BCG-Induced Cross-Protection and Development of Trained Immunity: Implication for Vaccine Design. Frontiers in Immunology. Frontiers Media S.A; 2019. p. 2806.

17. Redelman-Sidi G, Glickman MS, Bochner BH. The mechanism of action of BCG therapy for bladder cancer-A current perspective. Nature Reviews Urology. Nat Publ Group; 2014. p. 153162

18. Buffen K, Oosting M, Quintin J, Ng A, Kleinnijenhuis J, Kumar $\mathrm{V}$, et al. Autophagy Controls BCG-Induced Trained Immunity and the Response to Intravesical BCG Therapy for Bladder Cancer. Deretic V, editor. PLoS Pathogens [Internet]. Public Library of Science; 2014 [cited 2020 May 11];10:e1004485. Available from: https://dx.plos.org/10.1371/journal.ppat. 1004485

19. BCG vaccines 1 Report on BCG vaccine use for protection against mycobacterial infections including tuberculosis, leprosy, and other nontuberculous mycobacteria (NTM) infections Prepared by the SAGE Working Group on BCG Vaccines and WHO Secretariat. 2017

20. Search of: BCG | COVID-19 - List Results - ClinicalTrials.gov [Internet]. [cited 2020 Aug 27]. Available from: https:// clinicaltrials.gov/ct2/results?cond=COVID-19\&term $=$ BCG\&cntry $=\&$ state $=\&$ city $=\&$ dist $=$

21. Escobar LE, Molina-Cruz A, Barillas-Mury C. BCG vaccine protection from severe coronavirus disease 2019 (COVID-19). Proceedings of the National Academy of Sciences of the United States of America [Internet]. NLM (Medline); 2020 [cited 2020 Aug 23];117:17720-6. Available from: https://www.pnas.org/ content/117/30/17720

22. Gursel M, Gursel I. Is global BCG vaccination-induced trained immunity relevant to the progression of SARS-CoV-2 pandemic? [Internet]. Allergy: European Journal of Allergy and Clinical Immunology. Blackwell Publishing Ltd; 2020 [cited 2020 Aug 10]. p. 1815-9. Available from: https://www.ncbi.nlm.nih. gov/pmc/articles/PMC7267226/

23. Ozdemir G, Kucuksezer UC, Tamay ZU. Is BCG vaccination affecting the spread and severity of COVID-19? Allergy [Internet]. Blackwell Publishing Ltd; 2020 [cited 2020 Aug 10];75:1824-7. Available from: https://onlinelibrary.wiley. com/doi/abs/10.1111/all.14344

24. Raghab Mohapatra P, Mishra B, Behera B. BCG vaccination induced protection from COVID-19. Indian Journal of Tuberculosis [Internet]. Elsevier; 2020 [cited 2020 Aug 13]; Available from: https://linkinghub.elsevier.com/retrieve/pii/ S0019570720301323

25. Hajjo R, Setola V, Roth BL, Tropsha A. Chemocentric informatics approach to drug discovery: identification and experimental validation of selective estrogen receptor modulators as ligands of 5-hydroxytryptamine- 6 receptors and as potential cognition enhancers. J Med Chem. 2012;55.
26. Matsumiya M, Satti I, Chomka a, Harris SA, Stockdale L, Meyer J et al. Gene Expression and Cytokine Profile Correlate With Mycobacterial Growth in a Human BCG Challenge Model. 2014;

27. Subramanian A, Narayan R, Corsello SM, Peck DD, Natoli TE, Lu X, et al. A Next Generation Connectivity Map: L1000 Platform and the First 1,000,000 Profiles. Cell. Cell Press; 2017;171:1437-1452.e17.

28. Hollander M, Wolfe D. Nonparametric statistical methods. New York: Wiley; 1999. p. 178-85.

29. Liao FH, Shui JW, Hsing EW, Hsiao WY, Lin YC, Chan YC, et al. Protein phosphatase 4 is an essential positive regulator for Treg development, function, and protective gut immunity. Cell and Bioscience. BioMed Central Ltd; 2014;4:25.

30. Zhan Z, Gao H, Xie X, Yang L, Zhang P, Chen Y, et al. Phosphatase PP4 negatively regulates type I IFN production and antiviral innate immunity by dephosphorylating and deactivating TBK1. The Journal of Immunology The American Association of Immunologists. 2015;195:3849-57.

31. Quevedo M, Meert L, Dekker MR, Dekkers DHW, Brandsma JH, van den Berg DLC, et al. Mediator complex interaction partners organize the transcriptional network that defines neural stem cells. Nature Communications Nature Publishing Group. 2019;10:1-15.

32. Ellmeier W, Seiser C. Histone deacetylase function in CD4+ T cells. Nature Reviews Immunology. Nat Publ Group; 2018. p. 617-634.

33. Kwaa AK, Goldsborough K, Walker-Sperling VE, Pianowski LF, Gama L, Blankson JN. The effect of Ingenol-B on the suppressive capacity of elite suppressor HIV-specific CD8+ T cells. PLoS ONE Public Library of Science. 2017;12.

34. Hezareh M. Prostratin as a new therapeutic agent targeting HIV viral reservoirs. Drug News and Perspectives. Drug News Perspect; 2005. p. 496-500.

35. Sung TL, Rice AP. Effects of prostratin on Cyclin TI/P-TEFb function and the gene expression profile in primary resting CD4+ T cells. Retrovirology. BioMed Central; 2006;3:66.

36. Basta S, Knoetig S, Summerfield A, McCullough KC. Lipopolysaccharide and phorbol 12-myristate 13-acetate both impair monocyte differentiation, relating cellular function to virus susceptibility. Immunology Wiley-Blackwell. 2001;103:488-97.

37. Huang Z, Ye B, Han J, Kong F, Shan P, Lu Z, et al. NACHT, LRR and PYD domains-containing protein 3 inflammasome is activated and inhibited by berberine via toll-like receptor 4/ myeloid differentiation primary response gene 88/nuclear factor- $\mathrm{KB}$ pathway, in phorbol 12-myristate 13-acetate-induced macrophage. Mol Med Rep. 2018;17:2673-80.

38. Choy KT, Wong AYL, Kaewpreedee P, Sia SF, Chen D, Hui KPY, et al. Remdesivir, lopinavir, emetine, and homoharringtonine inhibit SARS-CoV-2 replication in vitro. Antiviral Research. Elsevier B.V.; 2020;178.

39. Pradhan P, Nguyen ML. Herpes simplex virus virucidal activity of MST-312 and epigallocatechin gallate. Virus Research. Elsevier B.V.; 2018;249:93-8.

40. Gabrielsen B, Monath TP, Huggins JW, Kefauver DF, Pettit GR, Groszek G, et al. Antiviral (RNA) activity of selected amaryllidaceae isoquinoline constituents and synthesis of related substances. J Nat Prod. 1992;55:1569-81.

41. Tamura G, Ando K, Takatsuki A, Arima K, Suzuki S. Antiviral activity of brefeldin A and verrucarin A. Journal of Antibiotics. 1968. p. 160-1.

42. Why lopinavir and hydroxychloroquine do not work on COVID19-ScienceDaily [Internet]. [cited 2020 Aug 10]. Available from: https: / /www.sciencedaily.com/releases/2020/07/ 200710112108.htm 
43. Marzolini G, Stader F, Stoeckle M, Franzeck F, Egli A, Bassetti S, et al. Effect of Systemic Inflammatory Response to SARS-CoV-2 on Lopinavir and Hydroxychloroquine Plasma Concentrations. Antimicrobial Agents and Chemotherapy [Internet]. 2020 [cited 2020 Aug 10]; Available from: http://aac.asm.org/lookup/doi/ 10.1128/AAC.01177-20

44. Schoergenhofer C, Jilma B, Stimpfl T, Karolyi M, Zoufaly A. Pharmacokinetics of Lopinavir and Ritonavir in Patients Hospitalized With Coronavirus Disease 2019 (COVID-19). Annals of Internal Medicine [Internet]. American College of Physicians; 2020 [cited 2020 Aug 10]; Available from: https:// www.acpjournals.org/doi/abs/10.7326/M20-1550

45. Guzzi PH, Mercatelli D, Geraolo C, Giorgi FM. Master Regulator Analysis of the SARS-CoV-2/Human Interactome. Journal of Clinical Medicine. MDPI AG; 2020;9:982.

46. Gordon DE, Jang GM, Bouhaddou M, Xu J, Obernier K, O'Meara MJ, et al. A SARS-CoV-2-Human Protein-Protein Interaction Map Reveals Drug Targets and Potential DrugRepurposing. bioRxiv [Internet]. Cold Spring Harbor Laboratory; 2020 [cited 2020 Apr 25];2020.03.22.002386. Available from: https://www.biorxiv.org/content/10.1101/ 2020.03.22.002386vl.full

47. McGovern ME, Canning D. Vaccination and All-Gause Child Mortality From 1985 to 2011: Global Evidence From the Demographic and Health Surveys. American Journal of Epidemiology [Internet]. Oxford University Press; 2015 [cited 2020 Aug 27];182:791-8. Available from: https://pubmed.ncbi. nlm.nih.gov/26453618/

48. Scheid A, Borriello F, Pietrasanta C, Christou H, Diray-Arce J, Pettengill MA, et al. Adjuvant effect of Bacille Calmette-Guérin on hepatitis B vaccine immunogenicity in the preterm and term newborn. Frontiers in Immunology [Internet]. Frontiers Media S.A.; 2018 [cited 2020 Aug 12];9:24. Available from: www. frontiersin.org

49. Shehadeh N, Etzioni A, Cahana A, Teninboum G, Gorodetsky B, Barzilai $\mathrm{D}$, et al. Repeated $\mathrm{BCG}$ vaccination is more effective than a single dose in preventing diabetes in non-obese diabetic (NOD) mice. undefined. 1997;

50. Uthayakumar D, Paris S, Chapat L, Freyburger L, Poulet H, de Luca K. Non-specific Effects of vaccines illustrated through the BCG example: from observations to demonstrations [Internet]. Frontiers in immunology. NLM (Medline); 2018 [cited 2020 Aug 12]. p. 2869. Available from: /pmc/articles/ PMC6288394/?report=abstract.

51. Faustman DL. Benefits of BCG-induced metabolic switch from oxidative phosphorylation to aerobic glycolysis in autoimmune and nervous system diseases. Journal of Internal Medicine [Internet]. Blackwell Publishing Ltd; 2020 [cited 2020 Aug 12];joim.13050. Available from: https://onlinelibrary.wiley. com/doi/abs/10.1111/joim.13050

52. Netea MG, van Crevel R. BCG-induced protection: Effects on innate immune memory [Internet]. Seminars in Immunology. Academic Press; 2014 [cited 2020 Aug 12]. p. 512-7. Available from: https://pubmed.ncbi.nlm.nih.gov/25444548/

53. Leentjens J, Kox M, Stokman R, Gerretsen J, Diavatopoulos DA, van Crevel $\mathrm{R}$, et al. BCG vaccination enhances the immunogenicity of subsequent influenza vaccination in healthy volunteers: A randomized, placebo-controlled pilot study. Journal of Infectious Diseases [Internet]. Oxford University Press; 2015 [cited 2020 Aug 12];212:1930-8. Available from: https://academic.oup. com/jid/article/212/12/1930/2911938

54. Ritz N, Mui M, Balloch A, Curtis N. Non-specific effect of Bacille Calmette-Guérin vaccine on the immune response to routine immunisations. Vaccine Elsevier. 2013;31:3098-103.

55. Ota MOC, Vekemans J, Schlegel-Haueter SE, Fielding K, Sanneh M, Kidd M, et al. Influence of mycobacterium bovis bacillus calmette-guérin on antibody and cytokine responses to human neonatal vaccination. The Journal of Immunology [Internet]. The American Association of Immunologists; 2002 [cited 2020 Aug 12];168:919-25. Available from: http://www. jimmunol.org/content/168/2/919

56. BCG vaccines 1 Report on BCG vaccine use for protection against mycobacterial infections including tuberculosis, leprosy, and other nontuberculous mycobacteria (NTM) infections Prepared by the SAGE Working Group on BCG Vaccines and WHO Secretariat. 2017.

57. Moorlag SJCFM, Arts RJW, van Crevel R, Netea MG. Nonspecific effects of BCG vaccine on viral infections [Internet]. Clinical Microbiology and Infection. Elsevier B.V.; 2019 [cited 2020 Aug 10]. p. 1473-8. Available from: https://pubmed.ncbi. nlm.nih.gov/31055165/

58. Arts RJW, Moorlag SJCFM, Novakovic B, Li Y, Wang SY, Oosting M, et al. BCG Vaccination Protects against Experimental Viral Infection in Humans through the Induction of Cytokines Associated with Trained Immunity. Cell Host and Microbe [Internet]. Cell Press; 2018 [cited 2020 Aug 10];23:89100.e5. Available from: https://pubmed.ncbi.nlm.nih.gov/ 29324233/

59. Kleinnijenhuis J, Quintin J, Preijers F, Joosten LAB, Ifrim DC, Saeed S, et al. Bacille Calmette-Guérin induces NOD2-dependent nonspecific protection from reinfection via epigenetic reprogramming of monocytes. Proceedings of the National Academy of Sciences of the United States of America. Proc Natl Acad Sci U S A. 2012;109:17537-42.

60. Aronson NE, Santosham M, Comstock GW, Howard RS, Moulton LH, Rhoades ER, et al. Long-term Efficacy of BCG Vaccine in American Indians and Alaska Natives: A 60-Year Follow-up Study. Journal of the American Medical Association. 2004. p. 2086-91.

61. Mateus J, Grifoni A, Tarke A, Sidney J, Ramirez SI, Dan JM, et al. Selective and cross-reactive SARS-CoV-2 T cell epitopes in unexposed humans. Science [Internet]. American Association for the Advancement of Science (AAAS); 2020 [cited 2020 Aug 27]; eabd3871. Available from: http://science.sciencemag. org/

62. Sekine T, Perez-Potti A, Rivera-Ballesteros O, Strålin K, Gorin J$\mathrm{B}$, Olsson A, et al. Robust T cell immunity in convalescent individuals with asymptomatic or mild COVID-19. Cell [Internet]. Elsevier; 2020 [cited 2020 Aug 27];0. Available from: https:// linkinghub.elsevier.com/retrieve/pii/S0092867420310084

63. Pavlidis P, Qin J, Arango V, Mann JJ, Sibille E. Using the gene ontology for microarray data mining: A comparison of methods and application to age effects in human prefrontal cortex [Internet]. Neurochemical Research. Springer; 2004 [cited 2020 Aug 23]. p. 1213-22. Available from: https://link.springer.com/ article/10.1023/B:NERE.0000023608.29741.45

64. Khatri P, Sirota M, Butte AJ. Ten Years of pathway analysis: current approaches and outstanding challenges. Ouzounis CA, editor. PLoS Computational Biology [nternet]. Public Library of Science; 2012 [cited 2020 Aug 23];8:e1002375. Available from: https://dx.plos.org/10.1371/journal.pcbi. 1002375

65. Barabási A-L, Oltvai ZN. Network biology: understanding the cell's functional organization. nature reviews | genetics [Internet]. 2004 [cited 2020 Aug 23];5:0-1. Available from: www.nature.com/reviews/genetics

66. Maleki F, Ovens K, Hogan DJ, Kusalik AJ. Gene set analysis: challenges, opportunities, and future research [Internet]. Frontiers in Genetics. Frontiers Media S.A.; 2020 [cited 2020 Aug 23]. p. 654. Available from: www.frontiersin.org

67. Albert R. Network inference, analysis, and modeling in systems biology [Internet]. Plant Cell. American Society of Plant 
Biologists; 2007 [cited 2020 Aug 23]. p. 3327-38. Available from: https://www.ncbi.nlm.nih.gov/pmc/articles/PMC2174897/

68. Ayoub BM. GOVID-19 vaccination clinical trials should consider multiple doses of BCG. Die Pharmazie [Internet]. 2020 [cited 2020 Apr 30];75:159. Available from: https://www.ncbi.nlm. nih.gov/pubmed/32295694.

69. GuiJ, Mustachio LM, Su DM, Craig RW. Thymus size and agerelated thymic involution: Early programming, sexual dimorphism, progenitors and stroma [Internet]. Aging and Disease. International Society on Aging and Disease; 2012 [cited 2020 Aug 23]. p. 280-90. Available from: https://www.pmc/articles/ PMC3375084/?report=abstract.

70. Belizário JE, Brandão W, Rossato C, Peron JP. Thymic and postthymic regulation of Naïve CD4+ T-cell lineage fates in humans and mice models. Mediators of Inflammation Hindawi Limited. 2016;2016.

71. Qi Q Zhang DW, Weyand CM, Goronzy JJ. Mechanisms shaping the naïve $\mathrm{T}$ cell repertoire in the elderly - Thymic involution or peripheral homeostatic proliferation? Experimental Gerontology. Elsevier Inc.; 2014;54:71-4.

72. Mangtani P, Nguipdop-Djomo P, Keogh RH, Sterne JA, Abubakar I, Smith PG, et al. The duration of protection of school-aged BCG vaccination in England: a population-based case-control study. 2017 [cited 2020 May 3]; Available from: https://academic.oup.com/ije/article-abstract/47/1/193/ 4098108

73. Nguipdop-Djomo P, Heldal E, Rodrigues LC, Abubakar I, Mangtani P. Duration of BCG protection against tuberculosis and change in effectiveness with time since vaccination in Norway: a retrospective population-based cohort study. The lancet infectious diseases. Lancet Publishing Group. 2016;16:21926.

74. Kagina BMN, Abel B, Bowmaker M, Scriba TJ, Gelderbloem S, Smit E, et al. Delaying BCG vaccination from birth to 10 weeks of age may result in an enhanced memory CD4 $\mathrm{T}$ cell response. Vaccine [Internet]. NIH Public Access; 2009 [cited 2020 Aug 24];27:5488-95. Available from: https://www.pmc/ articles/PMC2745558/?report=abstract.

75. Bull NC, Stylianou E, Kaveh DA, Pinpathomrat N, Pasricha J, Harrington-Kandt R, et al. Enhanced protection conferred by mucosal BCG vaccination associates with presence of antigenspecific lung tissue-resident PD-1 + KLRG1 - CD4 + T cells. Mucosal Immunology [Internet]. Nature Publishing Group; 2019 [cited 2020 Aug 27];12:555-64. Available from: https://doi.org/ 10.1038/s41385-018-0109-1.

76. Matsumiya M, Satti I, Chomka A, Harris SA, Stockdale L, Meyer $\mathrm{J}$, et al. Gene expression and cytokine profile correlate with mycobacterial growth in a human BCG challenge model. The Journal of Infectious Diseases [Internet]. 2015;211:1499-509 Available from: https://academic.oup.com/jid/article-lookup/doi/10. 1093/infdis/jiu615.

77. Shannon P, Markiel A, Ozier O, Baliga NS, Wang JT, Ramage $\mathrm{D}$, et al. Cytoscape: a software environment for integrated models of biomolecular interaction networks. Genome research. Cold Spring Harbor Laboratory Press. 2003;13:2498-504.

78. Szklarczyk D, Gable AL, Lyon D, Junge A, Wyder S, HuertaCepas J, et al. STRING v11: protein-protein association networks with increased coverage, supporting functional discovery in genome-wide experimental datasets. Nucleic Acids Res. 2018;47:D607-13.

79. Chatr-Aryamontri A, Ceol A, Palazzi LM, Nardelli G, Schneider MV, Castagnoli L, et al. MINT: the molecular INTeraction database. Nucleic Acids Res. 2006;35:D572-4.

80. Peri S, Navarro JD, Kristiansen TZ, Amanchy R, Surendranath V, Muthusamy B, et al. Human protein reference database as a discovery resource for proteomics. Nucleic acids research
[Internet]. 2004 [cited 2020 Apr 5];32:D497-501. Available from: https://www.ncbi.nlm.nih.gov/pubmed/14681466.

81. Bader GD, Betel D, Hogue GW v. BIND: the Biomolecular Interaction Network Database. [cited 2020 May 22]; Available from: http://www.ncbi.nlm.nih.

82. Xenarios I, Rice DW, Salwinski L, Baron MK, Marcotte EM, Eisenberg D. DIP: the database of interacting proteins [internet]. Nucleic Acids Res. 2000; Available from: http://dip.doe-mbi. ucla.edu/.

83. Breitkreutz B-J, Stark C, Reguly T, Boucher L, Breitkreutz A, Livstone M, et al. The BioGRID interaction database: 2008 update. Nucleic Acids Res. 2007;36:D637-40.

84. Kanehisa M, Araki M, Goto S, Hattori M, Hirakawa M, Itoh M, et al. KEGG for linking genomes to life and the environment. Nucleic Acids Res. 2007;36:D480-4.

85. Keseler IM, Collado-Vides J, Gama-Castro S, Ingraham J, Paley S, Paulsen IT, et al. EcoCyc: a comprehensive database resource for Escherichia coli. Nucleic Acids Res. 2005;33:D334-7.

86. Krupa S, Anthony K, BuchoffJ, Day M, Hannay T. Schaefer C. The NCI-Nature Pathway Interaction Database: A cell signaling resource. Nature Precedings. Springer Science and Business Media LLC; 2007. p. 1-1.

87. Consortium GO. The Gene Ontology (GO) database and informatics resource. [cited 2020 Apr 5]; Available from: www. geneontology.org/.

88. Nikolsky Y, Kirillov E, Zuev R, Rakhmatulin E, Nikolskaya T. Functional analysis of OMICs data and small molecule compounds in an integrated "knowledge-based" platform. Methods in molecular biology (Clifton, NJ). 2009;563:177-96.

89. Lamb J, Crawford ED, Peck D, Modell JW, Blat IC, Wrobel MJ, et al. The connectivity map: using gene-expression signatures to connect small molecules, genes, and disease. NY).: Science (New York; 2006.

90. Chindelevitch L, Ziemek D, Enayetallah A, Randhawa R, Sidders $\mathrm{B}$, Brockel C, et al. Causal reasoning on biological networks: interpreting transcriptional changes. 2012 [cited 2020 May 22];28: 1114-21. Available from: http://www.selventa.com

91. Pollard J, Butte AJ, Hoberman S, Joshi M, Levy J, Pappo J. A computational model to define the molecular causes of type 2 diabetes mellitus. Diabetes Technology and Therapeutics Diabetes Technol Ther. 2005; 7:323-36.

92. gplots package | R Documentation [Internet]. [cited 2020 Jan 24]. Available from: https://www.rdocumentation.org/ packages/gplots/versions/3.0.1.2

93. Wisskirchen K, Lucifora J, Michler T, Protzer U. New pharmacological strategies to fight enveloped viruses. Trends in Pharmacological Sciences. Elsevier Ltd; 2014. p. 470-478.

94. Barrows NJ, Campos RK, Powell ST, Prasanth KR, SchottLerner G, Soto-Acosta R, et al. A screen of FDA-approved drugs for inhibitors of Zika virus infection. Cell Host and Microbe Cell Press. 2016;20:259-70.

95. Tamura G, Ando K, Takatsuki A, Arima K, Suzuki S. Antiviral activity of brefeldin A and verrucarin A. Journal of Antibiotics. J Antibiot (Tokyo); 1968. p. 160-1.

96. Dyall J, Gross R, Kindrachuk J, Johnson RF, Olinger GG, Hensley LE, et al. Middle East respiratory syndrome and severe acute respiratory syndrome: current therapeutic options and potential targets for novel therapies. Drugs. Springer International Publishing; 2017. p. 1935-1966.

97. Ianevski A, Zusinaite E, Kuivanen S, Strand M, Lysvand H, Teppor M, et al. Novel activities of safe-in-human broadspectrum antiviral agents. Antiviral Research. Elsevier B.V.; 2018;154:174-82.

98. Farias KJS, Machado PRL, de Almeida Júnior RF, Lopes da Fonseca BA. Brefeldin A and Cytochalasin B reduce dengue virus replication in cell cultures but do not protect mice against viral 
challenge. Access Microbiology. Microbiology Society; 2019;1: e000041.

99. Yang S, Xu M, Lee EM, Gorshkov K, Shiryaev SA, He S, et al. Emetine inhibits Zika and Ebola virus infections through two molecular mechanisms: inhibiting viral replication and decreasing viral entry. Cell Discovery Nature Publishing Groups. 2018;4:1-14.
100. Dong HJ, Wang ZH, Meng W, Li CC, Hu YX, Zhou L, et al. The natural compound homoharringtonine presents broad antiviral activity in vitro and in vivo. Viruses MDPI AG. 2018;10.

Publisher's Note Springer Nature remains neutral with regard to jurisdictional claims in published maps and institutional affliations. 